\title{
High integrity mental health services for children: focusing on the person, not the problem
}

\author{
M Wolpert and colleagues discuss how the principles of high integrity healthcare can improve \\ mental health services for children and young people
}

\author{
M Wolpert professor in evidence based practice ${ }^{1}, \mathrm{P}$ Vostanis professor of child mental health ${ }^{2}, \mathrm{~K}$ \\ Martin director ${ }^{3}$, S Munk children and young people mental health and resilience strategic lead, ${ }^{4}$, \\ $\mathrm{R}$ Norman school improvement adviser ${ }^{5}$, P Fonagy professor of contemporary psychoanalysis and \\ developmental science ${ }^{1}$, A Feltham adviser ${ }^{3}$
} ${ }^{1}$ Research Department of Clinical, Educational, and Health Psychology, UCL, London, WC1E 6BT, UK; ${ }^{2}$ University of Leicester, Leicester, UK;
${ }^{3}$ Common Room, London, UK; ${ }^{4}$ London Borough of Newham, UK; ${ }^{5}$ London Borough of Lambeth, UK

\begin{abstract}
Around 1 in 10 children and young people worldwide have mental health difficulties that substantially affect their lives. Even in high income countries only a small minority of these people access specialist support, which has led to demands for more mental health specialists. ${ }^{1}$ We support these calls but think that focusing exclusively on the need for more healthcare professionals is not enough. We need to move away from approaches led by professionals that focus on problems towards care that is person centred and focused on progress.
\end{abstract}

In England some specialist provision is available from the NHS - publicly funded, free at the point of access—but the focus is increasingly on schools as key locations for provision (as is the case in many other high income countries), and on developing resilience in the community (as is the focus in many low and middle income countries). We can learn from the situation in England (box 1) as well as emerging international examples (box 2).

In 2016, The BMJ launched a wider call for high integrity healthcare, which emphasises that more services do not guarantee more health, that clinical evidence alone should not determine treatment, and that healthcare is best delivered by including non-health professionals. ${ }^{2}$ We consider these three challenges to conventional wisdom in terms of the way forward for provision of mental health services for children.

\section{More services don't guarantee more health}

\section{Treatment limitations}

Recovery rates in rigorously controlled trials for the most treatable difficulties, such as panic disorders, indicate that $30 \%$ of participants have not recovered at the end of treatment. For more treatment resistant difficulties, such as anorexia nervosa, this figure is closer to $50 \%{ }^{3}$ In UK and US studies of routine care in community, albeit based on flawed, uncertain, proximate, and sparse (FUPS) routinely collected data, 30\% or fewer indicate no symptoms at the end of treatment and around half show reliable improvement in symptom scores. ${ }^{4}$ Although the lack of positive outcomes in routine care may relate to the lack of appropriate use of evidence based treatment or sleeper effects, ${ }^{5}$ it might also be due to the limits of current treatment approaches for the range of problems seen in routine services. ${ }^{6}$

These low rates of positive outcomes may be seen as similar to those of chronic physical health conditions. For example, the recorded positive outcome rate of paediatric diabetes (based on control of HBA to under a threshold of 7.5) was $23.5 \%$ in 2014-15. ${ }^{7}$ However, the mental health field lacks the open discussion of treatment limitations. This may partly be because any discussion of treatment limitations is thought to threaten the limited funding that exists, but this mindset contributes to practitioners and patients feeling blamed for a lack of progress in treatment. ${ }^{8}$

We need a greater focus from the outset on the outcomes that young people want, with discussion of the likelihood of achieving them, given the current state of knowledge. Patients and mental health professionals should plan what to do if these outcomes are not achieved and have honest conversations about ways forward if there is no improvement.

\section{Potential for harm}

Until recently, the prevalent assumption was that, side effects notwithstanding, the majority of child mental health interventions were unreservedly good, with no potential for harm. This is increasingly being challenged, with calls to consider the potentially iatrogenic effects of overprovision and 


\section{Box 1: Provision of mental health services for young people in England}

Around a quarter of a million young people (up to age 24) and their parents or carers are seen in NHS specialist services for mental health across England each year. The numbers of young people accessing other forms of support are not available.

The most common difficulties for those accessing NHS services are family relationship difficulties, depression, and anxiety. Many have experienced abuse or trauma, and dedicated services exist for those in the care of the state, who are recognised to have particularly high levels of need and who may find it hard to engage with services. Most people who access services have more than one difficulty, and some are considered at high risk of harm from self or others.

For younger children, the focus is often on work with parents with or without the child present. Children, or their parents, are seen by one or more members of a multidisciplinary team, comprising psychiatrists, nurses, psychologists, therapists, or counsellors. They may be offered psychoeducation, talking therapies, behaviour change techniques, or medication. Treatment is mainly provided on an outpatient basis, with the majority of patients having fewer than six contacts and many being seen only once.

Mental health specialists are generally trained in face-to-face work, with little to no training in how to use emerging digital forms of support. Moreover, training puts greater emphasis on understanding the nature of the difficulties and how to engage people in therapy than on how to consider likely recovery rates or how to end therapy if substantial improvement isn't achieved and further improvement seems unlikely. Despite the goodwill and hard work of all those dedicated to supporting child mental health, integration of education, health, and social care is lacking.

\section{A former service user's view}

"Currently, children who use Child and Adolescent Mental Health Services (CAMHS) are often implicitly told that they are 'somebody else's problem.' GPs refer them to CAMHS. Schools don't provide any extra support, preferring to send them home when they are behaving differently from others. Youth clubs and other services are scared of them, the 'CAMHS kid' who might do something strange or dangerous at any minute. The world seems to expect that the child will go away to CAMHS, and come back fixed and ready to function normally. This is not fair on CAMHS or the child. Children recover in the same communities in which they got ill. Their environment may have contributed to their illness, or indeed changed because of it. Part of a child's recovery is transforming their environment into one that allows them to be well. Children cannot make this change on their own, thus support for the child in settings other than CAMHS is vital for recovery.

Support from other services builds the child's self esteem and encourages their return of normality. It allows the child to move from being 'somebody else's problem' to working with their family, wider community and environment towards a shared recovery."

\section{Box 2: Emerging international approaches}

Headspace (headspace.org.au) in Australia is a network of GPs, mental health workers, drug and alcohol services, and educational and vocational specialists that provides enhanced primary care for 12-25 year olds. This supports the principles of integrated working across sectors and support for self management at an early stage

"Jigsaw" sites (jigsaw.ie) in Ireland are a collaboration between primary care and ReachOut.Com (ie.reachout.com), an online youth mental health organisation. This supports both integration of services and digital initiatives to enable ongoing support

The Canadian ACCESS Open Minds network (cihr-irsc.gc.ca/e/49755.html) is a community driven approach that includes young people, family or carers, community organisations, service providers, researchers, policy makers, and decision makers. It provides help according to local needs and culture with a focus on engaging young people with emerging and established mental disorders

The Hussaini Foundation in Pakistan includes a pedagogical arm that provides training to parents, teachers and, more recently, staff at orphanages (hussainifoundation.org/education.php)

The World Awareness for Children in Trauma initiative (wacit.org) (led by PV) brings together models of best practice across some of the most economically disadvantaged communities in the world. Its objective is to develop a psychosocial service framework in the absence of specialist resources. It draws on existing strengths, such as community networks, schools and non-governmental providers, and adapts evidence based interventions to their sociocultural contexts

provision of ineffective support in psychological therapies in general. ${ }^{9}$ Initiatives such as Choosing Wisely (www. choosingwisely.co.uk) should be extended into child mental health. Practitioners may need to become more explicit about the need to monitor, including for harm, from the start of treatment. This idea is covered by the THRIVE framework, currently being trialled in England. The THRIVE framework is a way of conceptualising need among children, young people, and their families (table $1 \Downarrow$ ). Need is measured under five categories: thriving, getting advice, getting help, getting more help, and getting risk support. The model considers need as something that is "collaboratively agreed via a process of shared decision making" between the patient and the service provider rather than based on diagnosis or type of problem. ${ }^{10}$

Many of those accessing services are considered to be at substantial risk of harm whether by abuse or by self harm. So the focus of much service provision is on risk reduction and response. Anecdotal evidence from practitioners indicates that many of the most troubled children and young people are unable to benefit from the evidence based mental health treatment currently available, yet they are simply offered more therapy. This can lead to overprovision of unhelpful and even harmful health inputs. ${ }^{11}$ Emerging evidence suggests that simplifying, or even reducing, input may reduce costly inpatient admissions. ${ }^{12}$ The THRIVE framework advocates for more transparent discussion of the difference between treatment and risk support.

\section{Clinical evidence is not enough} Preference based care

The preferences of those accessing services should be a core part of decision making and health management and support. ${ }^{13}$ Shared decision making can be challenging due to considerations of developmental stage and mental capacity and its dissonance with traditional ways of working, ${ }^{14}$ but it may be particularly important for vulnerable children, such as those in the care of social services and those with experiences of abuse or neglect, whose interpersonal experiences have undermined their sense of control. Putting shared decision making at the centre of care may also be a more effective use of resources. Tools to support user voice and help choice in child mental health are starting to emerge. Box 3 gives some examples that we are involved in (box 3).

\section{Shared decision making}

Supporting shared decision making is imperative when the best approach is uncertain or untested, as is the case for much of child mental health input. Traditional healthcare assumes that research based guidance (such as the National Institute for Health and Care Excellence guidelines in the UK) can and should determine the best treatments. We support this approach and the important work done by NICE and other bodies. However, we found that NICE guidance was clearly relevant 


\section{Box 3: Examples of resources to support voice and choice}

My CAMHS Choices_-An online resource which has videos of young people and health professionals talking about their experience of receiving or providing CAMHS and mycamhschoices.org a resource to help people to consider what to expect when accessing specialist mental health services http://mycamhschoices.org/

Power Up-An app that enables young people to record and share ideas and decisions in ways that empower them to take a more active role in therapy. This is being developed using funding from an NIHR grant https://www.ucl.ac.uk/ebpu/research/PowerUp Choosing What's Best for You-Booklet and website designed for young people to explain the evidence base for different interventions (currently being updated) choosing.org.uk

Mefirst-Online resource to help professionals develop best ways to communicate with young people in a way to support shared decision making http://www.mefirst.org.uk

YouthWellbeing Directory-Helps children, parents and referrers find local and national services and sources of support and advice https://www.youthwellbeing.co.uk

Open Talk-Online resource which supports mental health professionals to involve children and young people in decisions about their care www.opentalk.info

for less than $38 \%$ of all children seen in specialist mental health services; the remaining $62 \%$ had difficulties that might be informed by NICE guidance, but it was not possible to find the information using an algorithm based on a sample of over 4000 children across 11 providers. ${ }^{15}$ Research in the US indicates that just over half of all young people accessing mental health services are clearly suitable for psychological treatments supported by empirical data. ${ }^{16}$

\section{Evaluating new approaches}

As we move beyond traditional face-to-face interventions, we need to draw on the increasing evidence for the role of social and economic factors in mental health (including, but not limited to, poverty, housing, neighbourhood cohesion, and national income inequality) to develop community resilience. ${ }^{17}$ Social prescribing (where patients are given non-medical "prescriptions" to services and activities in the community) and personal budgets (an amount of money to support patients' health and wellbeing needs, which is planned and agreed between the patient or representative and the NHS) are emerging ways to support a greater range of practices to promote mental health. ${ }^{18}$ However, these practices, including those in the community and in schools, must be rigorously evaluated so that appropriate comparisons can be made with current evidence based approaches.

One practical way to do this is to embed rigorous evaluation into any new approach being developed and to carry out randomised controlled trials wherever possible. For example, the HeadStart initiative (www.biglotteryfund.org.uk/headstart) focuses on innovative system-wide models to promote resilience and prevent mental health problems in 10-16 year olds, with interventions agreed by social care teams in collaboration with schools and healthcare providers. MW and KM are part of a learning team commissioned to work alongside healthcare providers to help to develop clear, one page logic diagrams (www.ucl.ac.uk/ebpu/docs/publication_files/EBPU-logic-model) that can be rigorously evaluated. This involves working with local authority project teams, including providers from health and education, to evaluate outcomes using an agreed common measurement framework (including annual self-report data on mental health and wellbeing from schools and information about services received) and to carry out specific randomised controlled trials over five years (www.annafreud.org/trainingresearch/research/improving-and-evaluating-services/headstart/ ). This ensures that new initiatives develop the robust evidence base required to determine if they achieve the desired outcomes.

\section{Input from non-healthcare professionals}

Parents may be particularly effective agents of change, especially for younger children. For example, the Centre for Parent and Child Support runs a programme called "Empowering Parents, Empowering Communities," which comprises an innovative peer led approach to enhance the capacity of parents to meet the challenges of children with behavioural problems. Engagement has been high, with 54 out of the 59 parents from some of the most vulnerable families in London completing it; the results are in line with parenting interventions led by healthcare professionals. ${ }^{19}$

Schools can also be a key site for mental health promotion, prevention, and intervention. ${ }^{20} \mathrm{~A}$ trial of over 10000 adolescents recruited from schools across Europe showed that the Youth Mental Health Awareness Programme reduced the incidence of suicide attempts, with the greatest benefits to countries with the least provision of mental health services for children. ${ }^{21}$ Peer mentoring programmes, whereby older adolescents mentor their younger peers, are increasingly used and are associated with positive emotional, social, and academic outcomes. ${ }^{22}$ Evidence on the efficacy of training teachers to deliver mental health interventions in schools is mixed, ${ }^{23}$ but guidance exists for schools on how to provide therapy, including through school counsellors and the use of innovative wellbeing hubs. ${ }^{24}$

Community support may be fostered by drop-in centres run by a mix of professionals and volunteers. Interest in new models of community support is growing, but these initiatives await rigorous evaluation. Drop-in sites, such as the recently established Pause centre in Birmingham, designed by and for young people, offer interesting alternatives to professional wisdom. For example, the young people asked for more open space rather than private rooms for discussions with counsellors, for there to be no reception desk, and for plenty of digital information that could be freely browsed (www. forwardthinkingbirmingham.org.uk/content/pause-hub).

Telephone and online resources are gradually emerging and are awaiting evaluation. The YoungMinds parents helpline offers free, confidential online and telephone support for adults worried about the mental health of a child or young person up to the age of 25. The evidence for digital support is mixed ${ }^{26}$; rigorous evaluation of emerging digital developments is a key priority.

\section{Measuring what matters}

Measuring mental health outcomes in children and young people is complex, given the diversity of the population, perspectives, measures, and metrics and the lack of control data and quality outcome data. 
For high integrity healthcare to become a reality and to underpin a change in mental health services for children, we need to focus on approaches beyond traditional healthcare. This would require researchers to develop a typology of mental health promoting practices that go wider than traditional healthcare interventions and to evaluate such practices to compare approaches for impact and cost effectiveness. Meanwhile, healthcare providers would have to be more explicit about limits of current treatments and focus more on self management and building and enhancing community support. This would involve: integrating agencies that are jointly concerned with the varied determinants of health; ensuring that rigorous consideration of service user preference and personalised goals underpin precision interventions and consideration of outcomes; and focusing on the strengths and assets of patients and their social networks.

Contributors and sources MW is a clinical psychologist by background and is committed to bridging the worlds of research and practice. MW is cofounder and director of the Child Outcomes Research Consortium, a collaboration of service providers committed to using evidence to improve practice. She also led on the development of the THRIVE model. PV is an international expert on the impact of trauma on child mental health, and evaluation of child mental health services. He currently leads World Awareness for Children in Trauma (WACIT), a global initiative started in 2015 (www.wacit.org). KM founded the consultancy Common Room in 2013. It comprises a network of young advisers who have experience of service use. KM won the UCL community engagement award (2016) for her work for the Evidence Based Practice Unit in engaging young people and service users. SM is a former hospital doctor and works at Newham local authority, leading the implementation of its CAMHS transformation plan, including the integration of CAMHS with voluntary sector, school, early years, and social care services. RN is a former head teacher of a secondary school and has a doctorate in education from King's College London. PF is national clinical adviser on child and adolescent mental health to NHS England and a senior investigator for the National Institute for Health Research. He is leader of the mental health theme in the North Thames Collaboration for Leadership in Applied Health Research and Care and director of research and development in the North East London Foundation Trust. AF is a psychology student and adviser for Common Room.

Competing interests: We have read and understood BMJ policy on declaration of interests and declare the following: $\mathrm{MW}$ is director of the Evidence Based Practice Unit and chair of CORC. MW and PF led development of the THRIVE model. PF was clinical lead and MW is informatics adviser for Children and Young People's Mental Health in NHS England. PF is in receipt of a National Institute for Health Research (NIHR) senior investigator award (NF-SI-0514-10157). PF and MW were in part supported by the NIHR Collaboration for Leadership in Applied Health Research and Care (CLAHRC) North Thames at Barts Health NHS Trust. The views expressed are those of the authors and not necessarily those of the NHS, the NIHR or the Department of Health.

Provenance and peer review: Commissioned; externally peer reviewed

Campion J, Bhugra D, Bailey S, Marmot M. Inequality and mental disorders: opportunities for action. Lancet 2013;357:183-4. doi:10.1016/S0140-6736(13)61411-7 pmid:23870520.
2 Mulley A, Richards T, Abbasi K. Delivering health with integrity of purpose. BMJ 2015;357:h4448. doi:10.1136/bmj.h4448 pmid:26283541.

3 Lambert MJ. Prevention of treatment failure: The use of measuring, monitoring, and feedback in clinical practice. American Psychological Association, 2010doi:10.1037/12141000 .

4 Wolpert M, Jacob J, Napoleone E, Whale A, Calderon A, Edbrooke-Childs J. Child- and parent-reported outcomes and experience from child and young people's mental health services 2011-15. 2016. http://www.corc.uk.net/information-hub/child-and-parent-reportedoutcomes-and-experience-from-child-and-young-people-s-mental-health-services-2011outcom 2015 .

5 Neufeld SA, Dunn VJ, Jones PB, Croudace TJ, Goodyer IM. Reduction in adolescent depression after contact with mental health services: a longitudinal cohort study in the UK. Lancet Psychiatry 2017;357:120-7. doi:10.1016/S2215-0366(17)30002-0 pmid: 28087201.

6 Warren JS, Nelson PL, Mondragon SA, Baldwin SA, Burlingame GM. Youth psychotherapy change trajectories and outcomes in usual care: Community mental health versus managed care settings. J Consult Clin Psychol 2010;357:144-55. doi:10.1037/a0018544 pmid: 20350026.

7 Royal College of Paediatrics and Child Health. National paediatric diabetes audit, 2015. http://www.rcpch.ac.uk/improving-child-health/quality-improvement-and-clinical-audit/ national-paediatric-diabetes-audit-n-0

8 Wolpert M. Failure is an option. Lancet Psychiatry 2016;357:510-2. doi:10.1016/S22150366(16)30075-X.

9 Crawford MJ, Thana L, Farquharson L, et al. Patient experience of negative effects of psychological treatment: results of a national survey. Br J Psychiatry 2016;357:260-5. doi:10.1192/bjp.bp.114.162628 pmid:26932486.

10 Wolpert M, Harris R, Hodges S, et al. Thrive elaborated. 2nd ed. CAMHS Press, 2016.

11 Bevington D, Fuggle P, Fonagy P. Applying attachment theory to effective practice with hard-to-reach youth: the AMBIT approach. Attach Hum Dev 2015;357:157-74. doi:10. 1080/14616734.2015.1006385 pmid:25782529.

12 Ungar M, Liebenberg L, Dudding P, Armstrong M, van de Vijver FJ. Patterns of service use, individual and contextual risk factors, and resilience among adolescents using multiple psychosocial services. Child Abuse Negl 2013;357:150-9. doi:10.1016/..chiabu.2012.05. 007 pmid:23260119.

13 Bickman L, Lyon AR, Wolpert M. Achieving precision mental health through effective assessment, monitoring, and feedback processes : Introduction to the special issue. Adm Policy Ment Health 2016;357:271-6. doi:10.1007/s10488-016-0718-5 pmid:26887937.

14 Drake RE, Deegan PE. Shared decision making is an ethical imperative. Psychiatr Serv 2009;357:1007-07. doi:10.1176/ps.2009.60.8.1007 pmid:19648184.

15 Wolpert M, Vostanis P, Young S, et al. Child and Adolescent Mental Health Services Payment System Project: Final Report. CAMHS Press, 2015.

16 Bernstein A, Chorpita BF, Daleiden EL, Ebesutani CK, Rosenblatt A. Building an evidence-informed service array: Considering evidence-based programs as well as their practice elements. J Consult Clin Psychol 2015;357:1085-96. doi:10.1037/ ccp0000029 pmid:26030761.

17 Friedli L. Mental health, resilience and inequalities. World Health Organization, Europe 2009.

18 Evans-Lacko S, Ribeiro W, Brietzke E, et al. Lean economies and innovation in mental health systems. Lancet 2016;357:1356-8. doi:10.1016/S0140-6736(16)30090-3 pmid: 27115800 .

19 Day C, Michelson D, Thomson S, Penney C, Draper L. Evaluation of a peer led parenting intervention for disruptive behaviour problems in children: community based randomised controlled trial. BMJ 2012;357:e1107. doi:10.1136/bmj.e1107 pmid:22416059.

20 Durlak JA, Weissberg RP, Dymnicki AB, Taylor RD, Schellinger KB. The impact of enhancing students' social and emotional learning: a meta-analysis of school-based universal interventions. Child Dev2011;357:405-32. doi:10.1111/j.1467-8624.2010.01564. x pmid:21291449.

21 Wasserman D, Hoven CW, Wasserman C, et al. School-based suicide prevention programmes: the SEYLE cluster-randomised, controlled trial. Lancet 2015;357:1536-44. doi:10.1016/S0140-6736(14)61213-7 pmid:25579833

22 DuBois DL, Portillo N, Rhodes JE, Silverthorn N, Valentine JC. How effective are mentoring programs for youth? A systematic assessment of the evidence. Psychol Sci Public Interest 2011;357:57-91. doi:10.1177/1529100611414806 pmid:26167708.

23 Stallard P, Skryabina E, Taylor G, et al. Classroom-based cognitive behaviour therapy (FRIENDS): a cluster randomised controlled trial to Prevent Anxiety in Children through Education in Schools (PACES). Lancet Psychiatry 2014;357:185-92. doi:10.1016/S22150366(14)70244-5 pmid:26360730.

24 Department for Education. Mental health and behaviour in schools: Departmental advice for school staff. Department for Education, 2015.

25 Department for Education. Counselling in schools: a blueprint for the future, 2015. https: //www.gov.uk/government/publications/counselling-in-schools

26 Hollis C, Falconer CJ, Martin JL, et al. Annual Research Review: Digital health interventions for children and young people with mental health problems: a systematic and meta-review. J Child Psychol Psychiatry 2017;357:474-503.pmid:27943285.

Accepted: 22032017

Published by the BMJ Publishing Group Limited. For permission to use (where not already granted under a licence) please go to http://group.bmj.com/group/rights-licensing/ permissions 


\section{Key messages}

Don't assume access to a specialist mental health professional will always be the best way to address mental health problems Ensure patients are active participants in making choices about their healthcare

Consider options for how to support mental health and wellbeing drawing on self, school, and community resources Measure what matters most to patients

\section{Table}

\section{Table 1| THRIVE framework for services}

\begin{tabular}{|c|c|c|}
\hline Prevailing assumptions & What THRIVE emphasises & Measurement implications \\
\hline $\begin{array}{l}\text { Higher levels of healthcare produce higher levels } \\
\text { of health and wellbeing for people and populations }\end{array}$ & $\begin{array}{l}\text { Role of education, social care and community } \\
\text { in supporting management of mental health } \\
\text { needs }\end{array}$ & $\begin{array}{l}\text { Measure degree of self management support available within } \\
\text { local community and extent of knowledge of these from health } \\
\text { providers and others }\end{array}$ \\
\hline $\begin{array}{l}\text { Clinical evidence tells us what is the right thing to } \\
\text { do for people in need of healthcare }\end{array}$ & $\begin{array}{l}\text { Need to base all care decisions on shared } \\
\text { decision making }\end{array}$ & $\begin{array}{l}\text { Choose measures of outcome that relate to the individual goals } \\
\text { of children and families which may mean that children with the } \\
\text { same presenting problems have different outcome measures }\end{array}$ \\
\hline $\begin{array}{l}\text { Healthcare is delivery of services by professionals } \\
\text { to people unable to understand or do it for } \\
\text { themselves }\end{array}$ & $\begin{array}{l}\text { Role of communities and individuals in } \\
\text { managing their own health }\end{array}$ & $\begin{array}{l}\text { Measure degree of involvement of those accessing services in } \\
\text { decision making and goal setting and amount of effort } \\
\text { professionals give to ensuring this takes place }\end{array}$ \\
\hline
\end{tabular}

http://www.corc.uk.net/media/1466/2016thrive_elaborated_2nd_edition.pdf 